\title{
Author Correction: Domestic horses (Equus caballus) prefer to approach humans displaying a submissive body posture rather than a dominant body posture
}

\author{
Amy Victoria Smith ${ }^{1}$ (D) Clara Wilson ${ }^{1} \cdot$ Karen McComb $^{1} \cdot$ Leanne Proops $^{1,2}$
}

Published online: 21 December 2017

๑) Springer-Verlag GmbH Germany, part of Springer Nature 2017

Author Correction: Anim Cogn

https://doi.org/10.1007/s10071-017-1140-4

In the original publication, data availability text was incorrectly published. The correct text should read as below.

Data availability:

Datasets generated during this study are available through the University of Sussex SURE data repository.

The original article can be found online at https://doi.org/10.1007/ s10071-017-1140-4.

Amy Victoria Smith

a.v.smith@sussex.ac.uk

$\triangle$ Leanne Proops

leanne.proops@port.ac.uk

1 Mammal Vocal Communication and Cognition Research

Group, School of Psychology, University of Sussex,

Brighton BN1 9QH, UK

2 Centre for Comparative and Evolutionary Psychology,

Department of Psychology, University of Portsmouth,

Portsmouth PO1 2DY, UK 